\title{
How to Pool Medical Services in Preventive Medicine Unit at 01/01/18 of Orléans Metropole/Orléans City Hall Structure: A Multi Disciplinary Network
}

\author{
Raphaël Serreau \\ City Hall Orleans, Preventive Medicine Unit, Orléans, France \\ Email: raphael.serreau@orleans-metropole.fr
}

How to cite this paper: Serreau, R. (2018) How to Pool Medical Services in Preventive Medicine Unit at 01/01/18 of Orléans Metropole/Orléans City Hall Structure: A Multi Disciplinary Network. Journal of Biosciences and Medicines, 6, 17-21. https://doi.org/10.4236/jbm.2018.61003

Received: August 28, 2017

Accepted: December 26, 2017

Published: December 29, 2017

\begin{abstract}
To reform the unit of preventive medicine in Orleans metropole, the Director of the Administration decided to co-sign an agreement to optimize the organization of a common preventive medicine service: we made a deliberation model to permit for others towns which wanted to join us. The cost evaluated to reach the service was the cost for medical examination, regardless of the professional which included staff costs and operating costs (social benefits, costs of supplies and materials, training costs). A statement of the tasks performed for the beneficiary community was kept daily by the SMP. A strong will of the Metropolis and municipalities is to develop a synergy around health and safety at work. A joint Metropolis of Orleans, an organization chart since 1/2/2016 integrates the preventive medicine service within a Quality of Life at Work service: a multidisciplinary service composed of prevention specialists, social workers, responsible for social action and SMP, a Department of Preventive Medicine was developed and itself multidisciplinary in accordance with the law of July 20, 2011: including doctors, nurses, psychologists, sophrologist, and a dietician. A new and active network of health is now operant with specialist correspondents. An audit is programmed in April 2018 to assess the efficacy of this network.
\end{abstract}

\section{Keywords}

Occupational Medicine, Preventive Medicine, Cost Efficiency Analysis, Multidisciplinary Network

\section{Introduction}

A network of public health doctors was created in 2013 with emergency physi- 
cians, toxicologists, addictologists and occupational physicians to coordinate the Department of Preventive Medicine in a full autonomy and independence of the administration of the local authority. The objectives of this network were to examine the agents and pronounce the compatibility at the workstation, to realize the post studies, in pairs with the IPRP and the Hygiene and Security engineer and to advise the employer on the arrangements to be made in connection with the Hygiene and Safety Manager. A full time physician animated the multidisciplinary team of Preventive Medicine (trainings, Staffs, meetings with HR).

The prevention doctor, head of department, runs a network of experts in Occupational Health, Addictions and Public Health in the Loire Valley region with IFPM and AP-HP, ANSES and GEGA in Paris.

The prevention/work doctor, according to article R 4623-1 of the Labor Code, is the employer's advisor for improving the living and working conditions in the company, to adapt positions, techniques and work rhythms to physical and mental health, to preserve the retention of employees, with the ergonomist, to protect workers against all nuisances, the risk of accidents at work, exposure to dangerous chemical agents.

The prevention/work doctor participates in the hygiene of the establishment and the catering services, and he participates in health education in the company related to the professional activity [1] [2]; he will give his agreement for new construction or improvements, setting up or modifying the organization of night work.

The prevention doctor carries out his missions in complete independence.

$\mathrm{He}$ conducts his actions in coordination with the employer, CHSCT or staff delegates the officer designated by the employer, competent to deal with the prevention of occupational these components, incorporating the applicable criteria that follow.

\section{Methodology}

\subsection{Professional Skills}

The nurses are state graduates: she have followed or will follow a training of health at work (DIUST) or by a tutoring with the doctors of prevention. She have prepared all periodic visits and at the request of the employer and the person concerned as well as the complementary examinations under the responsibility and the validation of the doctors of prevention.

She carried out public health actions on prevention campaigns and post studies under the control of preventive doctors.

She carried out a health and safety interview at work which is validated by the doctor:

She filled the "ESTIM protocol": health interview at nursing and medical work

She performed vaccinations DTCP, flu, leptospirosis by delegation of powers according to the regulations in force.

With the prevention doctor, she carried out ergonomics field studies in con- 
nection with the health and safety officer.

She managed medical equipment orders.

The psychologist carried out their job as a clinical psychologist with strict respect for confidentiality. At the request of the doctor and the nurses, they received the agents in situation of suffering and/or of burn-out.

She carried out preventive actions as part of the plan of prevention of the burn-out. She alerts the various interlocutors of the professional environment in case of suicidal risk. She conducted interviews for the authorization visit of the lethal weapon port. She conducted interviews according to questionnaires and validated scales (HAD scale). She supported the SMP team psychologically through formal and informal exchanges at team meetings. She worked with nursing students for input on psychological data.

The sophrologist performs his profession of sophrologist, on the individual level within his cabinet at the request of the SMP.

Perform training for the SMP team.

Is a force of proposition by its double competence to the human resources in the private one and sophrologist in connection with the work, during the institutional meetings to evaluate the stress at work.

Perform preventive actions.

Intervenes following the implementation of the plan to prevent RPS in November 2016.

The request for consultation is made by the agent directly to the sophrologist, the consultations are financed by the agent beyond the first 3 consultations.

The dietician performs her job as a dietician at the request of the agents, on the proposal of the SMP, the agents make an appointment.

Perform Public Health actions with IFPM nurses.

Works in conjunction with the various stakeholders of the SMP for the reduction of risk factors for PHI (sleep disorders, diet and sport)

Is proposal force for the SMP team and agents on an individual and collective level.

The secretaries organize the reception of the agents to the SMP.

Manage the schedules of the visits, the schedule of the meetings, the availability of the paper files via the kardex.

Coordinate dates of medical visits for doctors, psychologists, sophrologist, dietitian and nurses.

\subsection{Discussion}

The cohesion and multidisciplinarity of the teams allows a responsiveness to the so-called "sensitive" situations in order to act as quickly as possible in the interest of the agent and the community [3].

Possibility of deploying within the municipalities the procedure implemented since 2014 (4th version on 19/9/2017) within the Orléans City Council in agreement with the SAMU 45. 
Allows any person with OHS or not, to act with the doctor of the SAMU 45 to take care of a medical emergency.

Operational 24 hours a day, 7 days a week, use of the mobile phone.

OHS meeting days to perfect the formation of OHS.

Audited in May 2016, 93\% satisfaction, following a survey of the OHS both at the level of the City-AgglO and at the level of the platform of the SAMU 45 which validates the process.

Effective in speed of action, chaining responsibilities, quality of care and satisfaction of stakeholders.

Multidisciplinary and transdisciplinary team enters into action to develop the mutualisation, recognized by the bodies of HEALTH AT WORK of the local authorities [4] (medical committee, CDR, CDG, CDOM, ARS).

Achieving public health objectives to optimize the prevention of AT/MP, risk reduction with the health and safety officer [5].

Flexibility and adaptability in the management of pathologies by the multidisciplinary team.

Knowledge of the field through in-depth experience of trades and organizations.

Effective and responsive coordination with the outside: SAMU, CHRO, CHU, Universities, CDOM.

\section{Acknowledgements}

"R. Serreau thanks O Vernay and C Margolle for their help in the constitution of the network".

\section{References}

[1] Liu, L., Zhang, B., Lin, K., Zhang, Y., Xu, X. and Huo, X. (2017) Thyroid Disruption and Reduced Mental Development in Children from an Informal E-Waste Recycling Area: A Mediation Analysis. Chemosphere, 193, 498-505. https://doi.org/10.1016/j.chemosphere.2017.11.059

[2] Wallace, R.G., Twomey, L.C., Custaud, M.A., Turner, J., Moyna, N., Cummins, P.M. and Murphy, R.P. (2017) The Role of Epigenetics in Cardiovascular Health and Aging: A Focus on Physical Activity and Nutrition. Mech Ageing Dev. https://doi.org/10.1016/j.mad.2017.11.013

[3] Tam, G. and Yeung, M.P.S. (2017) A Systematic Review of the Long-Term Effectiveness of Work-Based Lifestyle Interventions to Tackle Overweight and Obesity. Prev Med. https://doi.org/10.1016/j.ypmed.2017.11.011

[4] Serreau, R., Maillard, T., Verdier, R., Bouchara, L., Catteau, C., Hervé, C., Fourmaintraux, A., Lamblin, D., Lesure, J.F. and Jacqz-Aigrain, E. (2002) Clinical Study and Prevalence of Fetal Alcohol Syndrome in Medico-Social Institutions of the Reunion Island. Arch Pediatr, 9, 14-20.

[5] Vacchina, V., Séby, F., Chekri, R., Verdeil, J., Dumont, J., Hulin, M., Sirot, V., Volatier, J.L., Serreau, R., Rousseau, A., Simon, T. and Guérin, T. (2017) Optimization and Validation of the Methods for the Total Mercury and Methylmercury Determination in Breast Milk. Talanta, 167, 404-410. https://doi.org/10.1016/j.talanta.2017.02.046 


\section{Abbreviations and Acronyms}

ANSES: French national agency for security of nutrition and working ARS: Regional health agency

CDG: Departmental health territorial agency

CDOM: Physician departmental agency

CDR: Disability departmental agency

CHRO: Regional hospital of Orleans

CHU: Regional University Hospital

DTCP: Diphteria Tetanos bordetella pertussis and cholera vaccine

ESTIM: Nurse and physician occupational questionnaire

GEGA: Addiction Pregnancy group in France

IFPM: Nurse university studies

SAMU: Emergency care

SMP: Preventive medicine center in Orléans 